\title{
ESTIMATION OF TSUNAMI FORCE ACTING ON THE BLOCK ARMORED BREAKWATER DUE TO SOLITON FISSION
}

\author{
Sohei Maruyama ${ }^{1}$, Tomotsuka Takayama ${ }^{2}$, Kenichiro Shimosako ${ }^{3}$, \\ Akihiko Yahiro $^{2}$, Kojiro Suzuki ${ }^{3}$, Toru Aota ${ }^{1}$, \\ Masashi Tanaka ${ }^{2}$, Akira Matsumoto ${ }^{1}$ and Minoru Hanzawa
}

\begin{abstract}
A series of hydraulic model experiments were performed to verify the effect of armoring concrete blocks on tsunami pressure reduction in a state of soliton fission. Applicable ranges for the Tanimoto and modified Tanimoto formulas for wave pressures acting on a caisson have been determined in terms of the ratio of tsunami height to water depth. An estimation formula for the tsunami pressure reduction factor of the armoring blocks was proposed as a result of a comparison of tsunami force between the states without and with the armoring blocks. The calculated tsunami forces acting on a caisson armored with blocks agreed well with the corresponding experimental ones. Sufficient stability of the armoring blocks against tsunamis was also confirmed by the experiments.
\end{abstract}

Keywords: tsunami, soliton fission, wave force, wave-dissipating works

\section{INTRODUCTION}

Establishment of a design method for breakwaters against tsunami is an urgent issue. Although tsunami forces on vertical caisson walls can be predicted by the already proposed empirical formula, the forces acting on caisson walls armored with wave-dissipating work (hereafter referred to as WDW) have not yet been verified sufficiently in experiments. The Guidelines for Tsunami-Resistant Design of Breakwaters (MLIT, 2013) suggests that WDW may reduce impulsive wave forces of a tsunami with soliton fission.

Murota and Iwata (1968) theoretically explained soliton fission as the dispersion mechanism from an ideal bore. Relating to tsunami disaster prevention, Iwasaki et al. $(1977,1978)$ investigated the tsunami deformation process of both generation and propagation in the near-coast offshore region. In 1983, a tsunami caused by the Nihonkai Chubu Earthquake hit the coast along the Japan Sea. At that time, the occurrence of soliton fission was clearly observed. (Shuto, 1984) Tanimoto et al. (1984) investigated actual conditions of tsunami attacks and damage to coastal structures. Based on analysis of the damage to a sea wall under construction, a tsunami pressure formula acting on a vertical wall due to a non soliton fission tsunami was proposed. Ikeno et al. (2006) proposed a new pressure formula for tsunami impulsive pressure taking into account the shoaling and breaking of a tsunami with soliton fission. Yasuda et al. (2006) examined the effect of the water depth on the run-up and pressure of a soliton fission tsunami which travelled in a uniform shallow depth on a reef topography. Kashima and Hirayama (2013) conducted hydraulic model experiments and numerical simulations to investigate the characteristics of a tsunami with soliton fission in Kuji harbor as observed in the Great East Japan Earthquake of 2011. They discussed generation and propagation of soliton fission and the impulsive tsunami force acting on the breakwaters.

As mentioned above, many studies have been conducted on tsunami forces acting on vertical breakwaters without WDW in front. However, in Japan, many breakwaters are armored with WDW to reduce the wave pressure. Even now, tsunami forces acting on such a block armored breakwater are not clear. For this reason, establishment of a design method for block armored breakwaters against tsunami is an urgent issue. As a result, Maruyama et al. (2015) conducted hydraulic model experiments on the tsunami wave force acting on the block armored breakwater. However, since their research aimed to clarify the fundamental characteristics of the tsunami wave with soliton fission, methods for calculating wave forces available for practical design work have not been proposed. Therefore in the present study, a series of hydraulic model experiments were conducted to establish an estimation method for tsunami wave forces acting on a block armored breakwater. First, the process of tsunami deformation was examined to understand the characteristics of tsunami profiles at soliton fission under a wide range of water depths and wave periods. Then, the tsunami wave pressure acting on a vertical caisson without armor blocks was measured to investigate the applicable ranges of Tanimoto formula (Tanimoto et al., 1984) or modified Tanimoto formula (MLIT, 2013). After these, the effect of

\footnotetext{
${ }^{1}$ Fudo Tetra Corporation, 2-7, Higashi Nakanuki, Tsuchiura, Ibaraki, 300-0006, Japan

${ }^{2}$ Coastal Development Institute of Technology, 1-14-2, Nishi Shinbashi, Minato, Tokyo, 105-0003, Japan

${ }^{3}$ Port and Airport Research Institute, 3-1-1, Nagase, Yokosuka, Kanagawa, 239-0826, Japan
} 
concrete blocks on tsunami force reduction was investigated by comparing the tsunami forces acting on the caisson with and without WDW. Finally, a tsunami wave force estimation formula was proposed by introducing the reduction factor into an existing empirical formula for tsunami pressure. The sufficient stability of the wave-dissipating blocks against tsunami has been also confirmed by the experiments.

\section{TSUNAMI DEFORMATION PASSING OVER A HORIZONTAL BED}

\section{Experimental Conditions}

Experiments were carried out in a wave flume, $50 \mathrm{~m}$ long, $1.0 \mathrm{~m}$ wide, and $1.5 \mathrm{~m}$ deep as shown in Figure 1. The tsunami was generated by using a piston type wave-maker driven in a half sinusoidal motion to reproduce a single hump of water. The amplitude of the wave paddle motion $S$ was set to the constant value of $39 \mathrm{~cm}$ and the wave period $T$ was varied from 8 to $28 \mathrm{~s}$. Therefore the amplitude of the generated tsunami differs depending on the period. Table 1 shows the experimental conditions.

\section{Experimental Results}

At the beginning, deformation of the generated tsunami with a single hump of water was observed. Soliton fission first occurred in the shallow uniform depth. Then, the solitons grew gradually with their propagation. They finally began to break away from larger ones. Figures 2 and 3 show examples of time historical profiles of a tsunami at different measurement points during its propagation. The measurement point at $x=9 \mathrm{~m}$ corresponds to just shoulder of the uniform reef and both tsunami profiles at this point do not include affection of soliton fission, as shown in Figures 2 and 3. Representing the height at the highest point of the tsunami profile above still water level as $\eta_{\mathrm{c}}$ and the water depth on the reef as $h$, the heights at $x=9 \mathrm{~m}$ in Figures 2 and 3 are given as $\eta_{\mathrm{c}} / h=0.5$ in Figure 2 and $\eta_{\mathrm{c}} / h=0.3$ in Figure 3 in non-dimensional form. In both cases, soliton fission is observed at $x=15 \mathrm{~m}$ point. Second and third solitons were born as it propagated onshore, and also the height of the highest point gradually increase with the propagation. In figure 2, the first soliton which corresponds to the highest point breaks between two points at $x=20 \mathrm{~m}$ and $25 \mathrm{~m}$, because the value of $\eta_{\mathrm{c}} / \mathrm{h}$ reach to 0.8 of breaking index of solitary wave. Then the second soliton becomes highest and it breaks between $x=25 \mathrm{~m}$ and $30 \mathrm{~m}$. The breaker, which was of spilling type, collapsed gently from the wave crest. The broken soliton resumes development by the energy supply from the main tsunami. On the other hand, in Figure 3, no breaking happens due to the deeper water depth of $28 \mathrm{~cm}$, and a group of solitons continue to increase without breaking.

Figure 4 shows a comparison between an experimental profile of a first soliton and the theoretical one of a solitary wave. The latter is expressed by the following formulas:

$$
\begin{aligned}
\eta(x, t) & =H \sec h^{2} \kappa(x-c t) \\
c & =\sqrt{g(h+H)} \\
\kappa & =\sqrt{3 H / 4 h^{3}}
\end{aligned}
$$

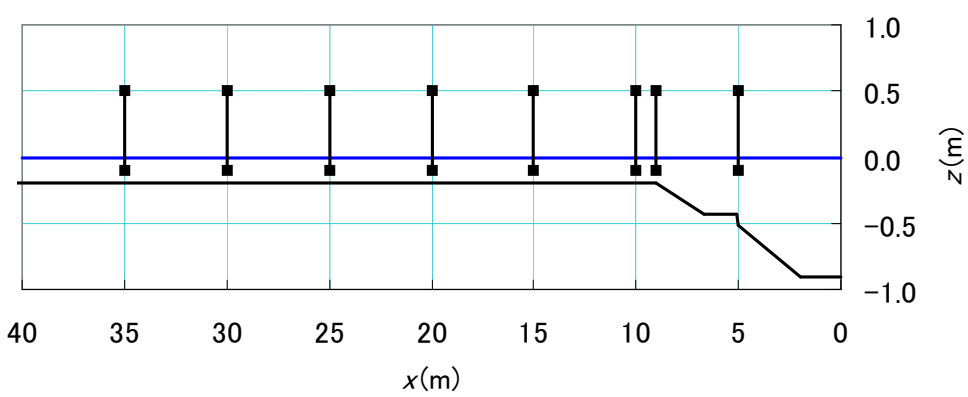

Figure 1. Wave flume setup.

where $h, H$ and $g$ denote the water depth, the wave height of the first soliton, and the gravitational acceleration, respectively. The experimental profile agrees well with the theoretical one. Even in other different conditions of water depth and wave period, the profiles kept the same. It has been recognized that the occurrence position of soliton fission depends on the relative amplitude of a tsunami to the water depth, and the total number of solitons is affected by the tsunami travelling distance. However, it 
should be noted here that even if the water depth and the motion of the wave paddle differed, the profile of the first soliton can be well expressed by the solitary wave theory as mentioned previously. This means that the position of the breakwater model and the period of the paddle motion can be set freely in experiments on tsunami force.

\begin{tabular}{|c|c|l|}
\hline \multicolumn{3}{|c|}{ Table 1. Experimental conditions. } \\
\hline Case & Water depth $h(\mathrm{~cm})$ & Wave period $T(\mathrm{~s})$ \\
\hline 1 & 10 & $22,24,26,28$ \\
\hline 2 & 12 & $20,22,24,26$ \\
\hline 3 & 16 & $14,18,20$ \\
\hline 4 & 20 & $12,14,16,18,20$ \\
\hline 5 & 24 & $10,12,14$ \\
\hline 6 & 28 & $8,10,12$ \\
\hline
\end{tabular}

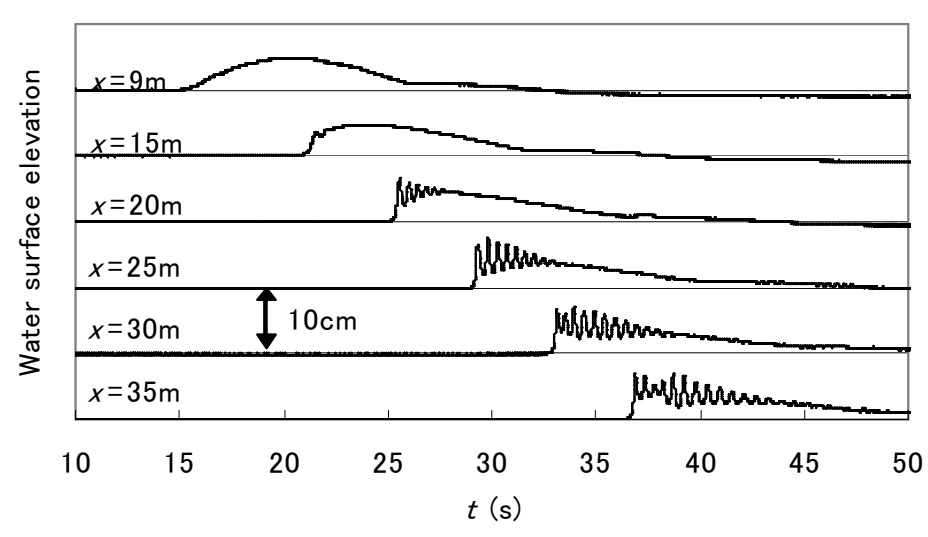

Figure 2. Time historical profiles of tsunami. $(h=10 \mathrm{~cm}, T=22 \mathrm{~s})$

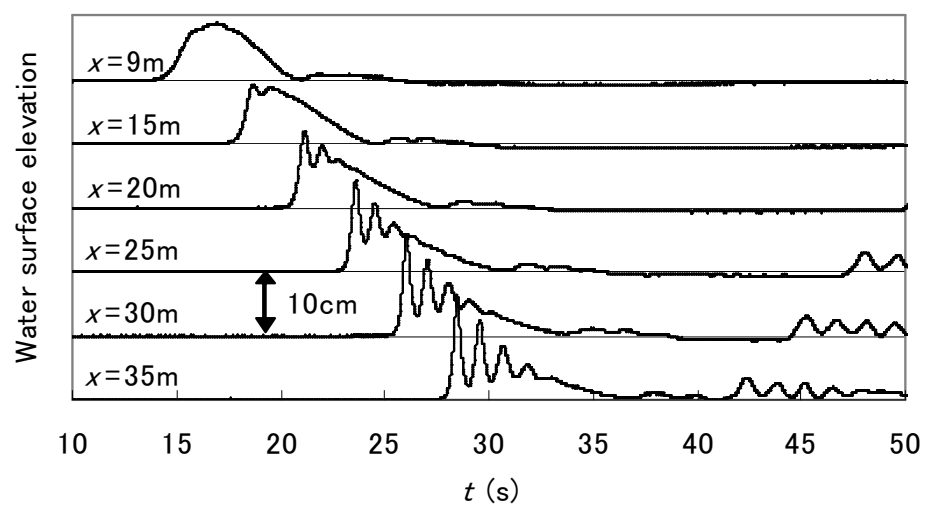

Figure 3. Time historical profiles of tsunami. ( $h=28 \mathrm{~cm}, T=12 \mathrm{~s})$

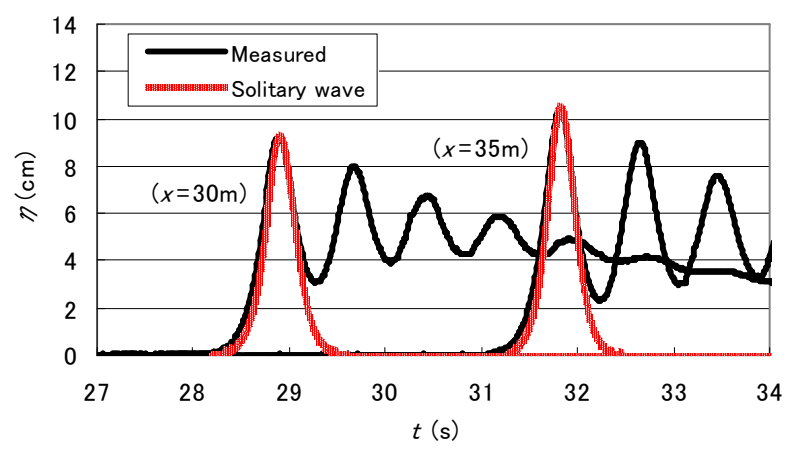

Figure 4. Comparison of measured and theoretical profile of the first soliton. 


\section{EXPERIMENTS ON THE TSUNAMI WAVE FORCE}

\section{Experimental Conditions}

A horizontal mortar seabed was partitioned into two waterways of $40 \mathrm{~cm}$ and $60 \mathrm{~cm}$ wide. A breakwater model was installed in the waterway of $60 \mathrm{~cm}$ wide. The position of the front wall of the caisson was at $x=34 \mathrm{~m}$. The incident wave acting on the breakwater was measured in the other waterway. The tsunami force and pressure distribution acting on the caisson were measured by using a 3-component force transducer and wave pressure gauges, respectively. The sampling frequency was set to $1000 \mathrm{~Hz}$. Measurements were repeated three times to compensate for deviation in the data and their mean values are used for analysis. Tables 2 summarizes the dimensions of the breakwater model in prototype scale. The mass of a Tetrapod was estimated by the Hudson formula under the wind wave height and stability constant. Figure 5 shows a cross section of the breakwater model. In the following, the applicable ranges of existing formulas for wave pressure acting on a vertical wall of caisson breakwaters without WDW are verified. Then, the estimation formula for the tsunami pressure reduction factor of the armoring blocks is proposed.

\begin{tabular}{|c|c|c|c|c|c|c|c|}
\hline \multicolumn{8}{|c|}{ Table 2. Dimensions of breakwater models. } \\
\hline Case & $\begin{array}{c}\text { Water } \\
\text { depth } \\
h(\mathrm{~m})\end{array}$ & $\begin{array}{c}\text { Mound } \\
\text { depth } \\
h^{\prime}(\mathrm{m})\end{array}$ & $\begin{array}{c}\text { Design } \\
\text { wave } \\
\text { height } \\
H_{\mathrm{D}}(\mathrm{m}) \\
\end{array}$ & Cro & $\begin{array}{l}\text { eight of } \\
\text { son } \\
\text { m) }\end{array}$ & $\begin{array}{c}\text { Block } \\
\text { mass } \\
M(\mathrm{t})\end{array}$ & $\begin{array}{l}\text { Crown } \\
\text { width } \\
\text { of WDW } \\
B(\mathrm{~m})\end{array}$ \\
\hline $1-1$ & \multirow[b]{2}{*}{8.0} & \multirow[b]{2}{*}{5.6} & \multirow[b]{2}{*}{4.6} & & $\left(0.6 H_{D}\right)$ & \multirow[b]{2}{*}{12.3} & \multirow{2}{*}{4.0} \\
\hline $1-2$ & & & & 4.6 & $\left(1.0 H_{D}\right)$ & & \\
\hline $2-1$ & \multirow{2}{*}{10.0} & \multirow{2}{*}{7.0} & \multirow{2}{*}{5.7} & 3.5 & $\left(0.6 H_{D}\right)$ & \multirow{2}{*}{23.0} & \multirow{2}{*}{5.0} \\
\hline $2-2$ & & & & 5.7 & $\left(1.0 H_{D}\right)$ & & \\
\hline $3-1$ & \multirow{2}{*}{12.0} & \multirow{2}{*}{8.4} & \multirow{2}{*}{6.9} & 4.1 & $\left(0.6 H_{D}\right)$ & \multirow{2}{*}{36.8} & \multirow{2}{*}{5.9} \\
\hline $3-2$ & & & & 6.9 & $\left(1.0 H_{D}\right)$ & & \\
\hline
\end{tabular}

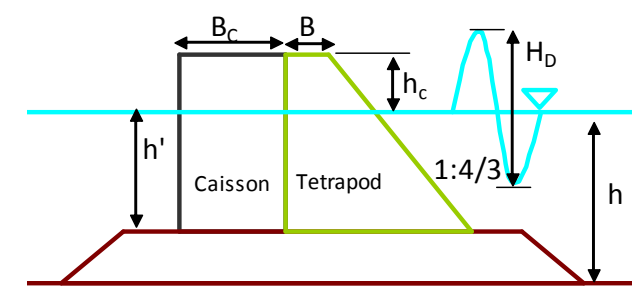

Figure 5. Cross section of breakwater model.

\section{Definition of The Incident Tsunami Height}

The incident tsunami height $a_{\mathrm{I}}$ will be used in the following discussion. Therefore, it has to be explicitly defined. In the practical design, in order to determine the tsunami wave force, the incident tsunami height obtained by numerical simulation is generally used. To represent the incident tsunami height $a_{\mathrm{I}}$ from the measured soliton wave neglecting the effect of soliton fission, a method of the moving average was taken to the time history of the water surface elevation and its maximum value was defined as the incident tsunami height in the same manner as Yasuda et al. (2006). Figure 6 schematically shows the definition of the incident tsunami height. The time average duration $\tau$ was adopted as $1.0 \mathrm{~s}$ in the model scale which corresponds to the representative wave period of first soliton.

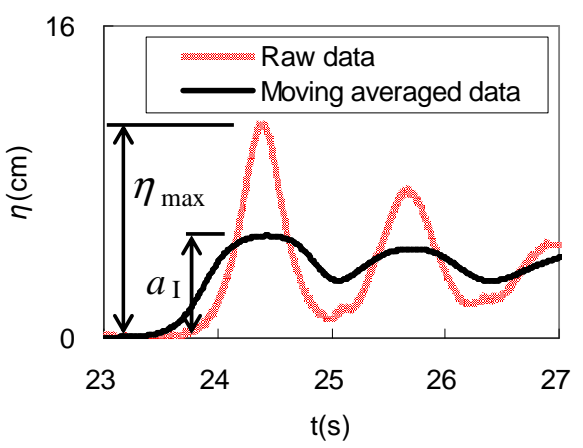

Figure 6. Definition of Incident Tsunami Height. 


\section{Fundamental Natures of Tsunami Wave Force with Soliton Fission}

A time series of water surface elevation, horizontal and vertical forces obtained by the 3component force transducer are shown in Figures 7 (a) and (b) for non-breaking and breaking wave conditions. In these figures, the time series of wave force with and without WDW are represented by blue and red lines, respectively. In the case of non-breaking, significant soliton fission was observed at the breakwater installation position. The time series of horizontal force varied corresponding to the variation of the water surface. In the case of breaking, the amplitude of the tsunami and that of the $1 \mathrm{st}$ soliton were comparable because of the breaking of the soliton. The wave force corresponding to each soliton wave shows the superposition to the force of the tsunami of a long period. The impulsive force observed around $t=26$ and 27s without WDW disappeared for the case with WDW. Consequently the tsunami force reducing effect of WDW was confirmed by the experiments. Figures 8 (a) and (b) show the simultaneous vertical pressure distributions at the time of maximum sliding force in the cases of Figures 7 (a) and (b). In the breaking condition, the effect of WDW was remarkable in the underwater portion.

As mentioned above, the fundamental characteristics of a tsunami with soliton fission for both the vertical and block armored breakwaters have thus been revealed. Following this, an easy-to-handle design method for breakwaters with WDW against tsunami with soliton fission will be established.
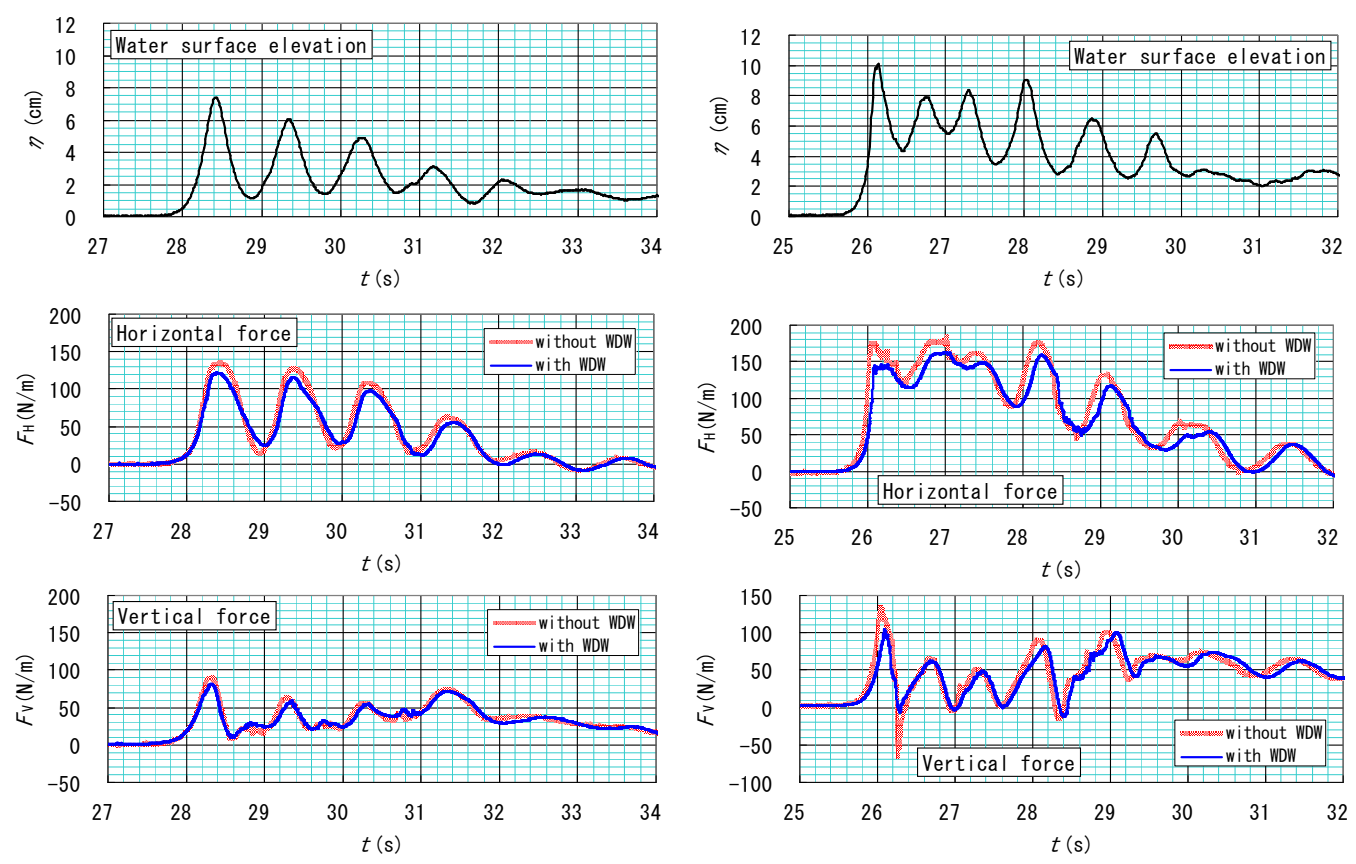

(a) Non-breaking

(b) Breaking

Figure 7. Examples of time series of water surface elevation and wave forces. (Case 1-1)

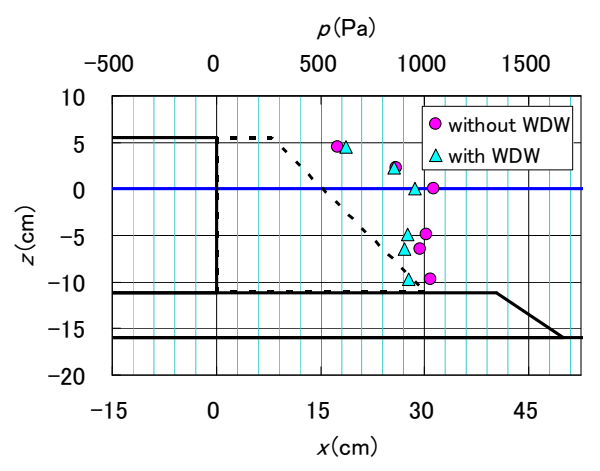

(a) Non-breaking

Figure 8. Examples of instantaneous wave pressure distribution. (Case 1-1)

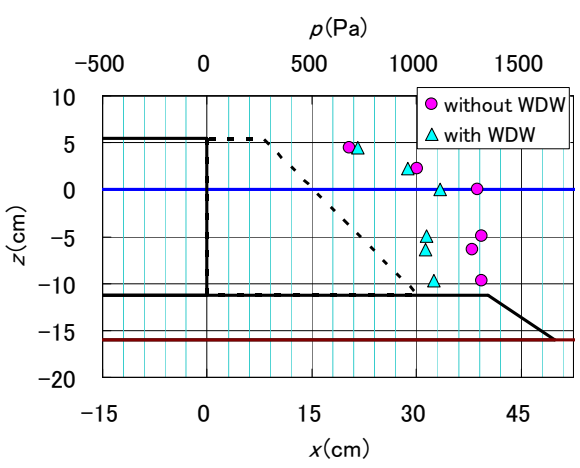

(b) Breaking
distribution. (Case 1-1) 


\section{Applicable Ranges of Existing Formulas for Vertical Breakwater}

Figure 9 shows the tsunami pressure distribution adopted in the Tanimoto formula (Tanimoto et al., 1984) and Modified Tanimoto formula (MLIT, 2013) for a vertical caisson wall without concrete blocks. Tanimoto et al. (1984) proposed a tsunami pressure formula acting on a vertical wall due to a non soliton fission tsunami as shown in the following equations:

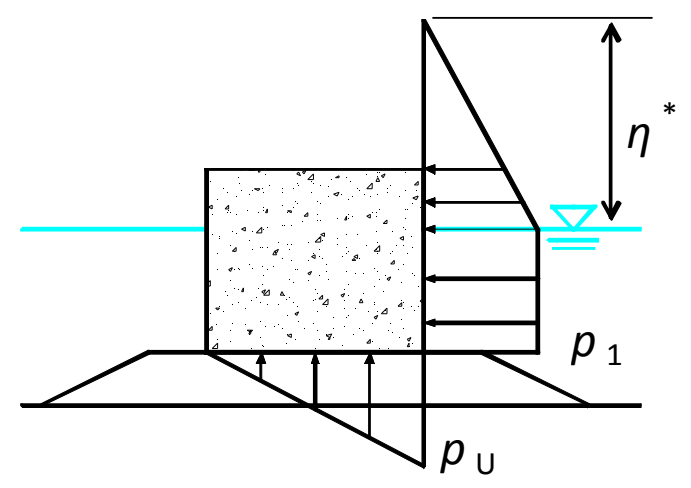

Figure 9. Pressure distributions in existing formulas.

$$
\begin{gathered}
\eta^{*}=3.0 a_{I} \\
p_{1}=2.2 \rho g a_{I} \\
p_{u}=p_{1}
\end{gathered}
$$

where $\eta^{*}$ is the acting height of wave pressure, $p_{1}$ is the horizontal wave pressure under the still water level, $p_{\mathrm{u}}$ is the uplift pressure at the toe of the caisson respectively. The value of $a_{\mathrm{I}}$ denotes the incident tsunami height, $\rho$ is the density of the water. On the other hand, in the case of soliton fission tsunami, Modified Tanimoto formula was suggested by the Guidelines for tsunami-resistant design of breakwater (MLIT, 2013). In this formula, the coefficient 2.2 for $p_{1}$ is replaced by 3.0 as shown in the following equation:

$$
p_{1}=3.0 \rho g a_{I}
$$

This increase in the horizontal pressure corresponds to the impulsive pressure due to soliton fission. However, the application ranges for these two formulas were not clear. The occurrence conditions of soliton-fission is usually judged by the tsunami height to water depth ratio $a_{\mathrm{I}} / h$. The boundary is usually set as 0.3 . However this 0.3 is an approximate value and can vary depending on other conditions. Therefore in this study, the wave pressure formula for $p_{1}$ is set in the following by using the horizontal pressure coefficient $\alpha$ and the properties of $\alpha$ is investigated based on the wave pressure data in various conditions of tsunami wave heights to water depth ratios $a_{\mathrm{I}} / h$.

$$
p_{1}=\alpha \rho g a_{I}
$$

Figures 10 (a) and (b) show the vertical distributions of wave pressure at the front face of the caisson. Figure 10 (a) shows the result of the normal conditions where the crown height of the caisson above the still water level is 0.6 times higher than the design wave height. On the other hand, Fig. 10 (b) shows the result when the crown height of the caisson is same as the design wave height. These figures clearly indicate the dependence of $\alpha$ on the value of $a_{\mathrm{I}} / h$. When $a_{\mathrm{I}} / h$ is smaller than 0.15 , the measured wave pressure data are distributed near the Tanimoto formula. On the other hand, they are distributed near the Modified Tanimoto formula for the values of $a_{\mathrm{I}} / h$ larger than 0.25 . When $a_{\mathrm{I}} / h$ is between 0.15 and 0.25 , they scattered between Tanimoto formula and Modified Tanimoto formula. These results show that soliton fission begins to occur at $a_{\mathrm{I}} / h=0.15$. Even if $a_{\mathrm{I}} / h$ is larger than 0.25 , data distributes near the Tanimoto formula for the wave breaking. It can be considered that the acting height of the wave pressure $\eta^{*}$ is $3.0 a_{\mathrm{I}}$ regardless of the condition of $a_{\mathrm{I}} / h$. 
As for the uplift pressure, original Tanimoto formula can be used in independence of the value of $a_{\mathrm{I}} / h$. Figure 11 shows the horizontal distribution of the non-dimensional uplift pressure to the distance normalized by the caisson width $B_{\mathrm{C}}$. As shown in Figure 11, the horizontal distribution of the uplift pressure is well represented by a triangular shape, where the uplift pressure is zero at the rear face and maximum at front face. On the bottom surface of the caisson, since a wave reduction effect of the rubble mound can be expected, it is unlikely that an impulsive pressure component will be generated there. From Figures 10(a) and (b), it can be seen that the value of $\alpha$ of the horizontal pressure decreases as it moves downward to the bottom of the caisson and approaches 2.2 near the rubble mound. In fact, from Figure 11, it can be concluded that the value of $\alpha$ in the modified Tanimoto formula is a little exaggerative to the data obtained in this experiments. The original Tanimoto formula well represents the overall behavior of uplift pressure.

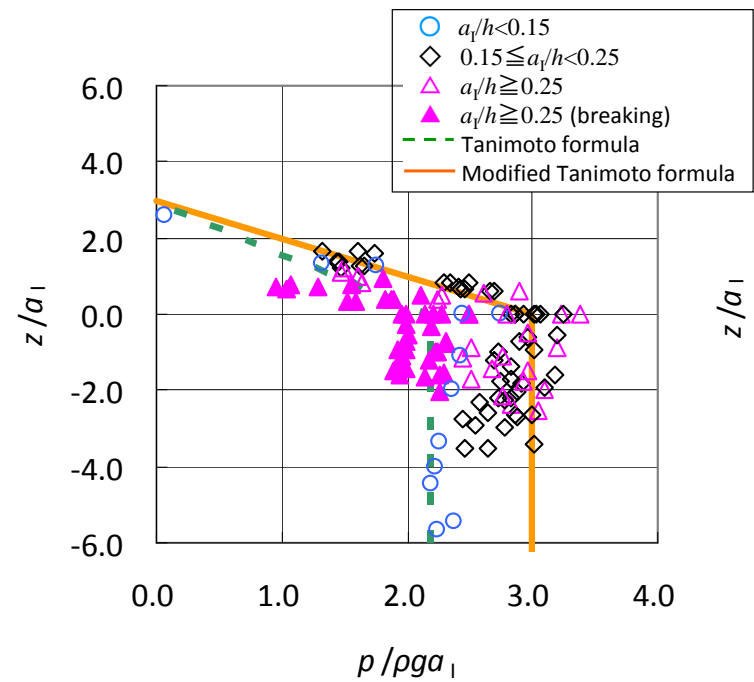

(a) Ordinary caisson $\left(h_{\mathrm{C}} / H_{\mathrm{D}}=0.6\right)$

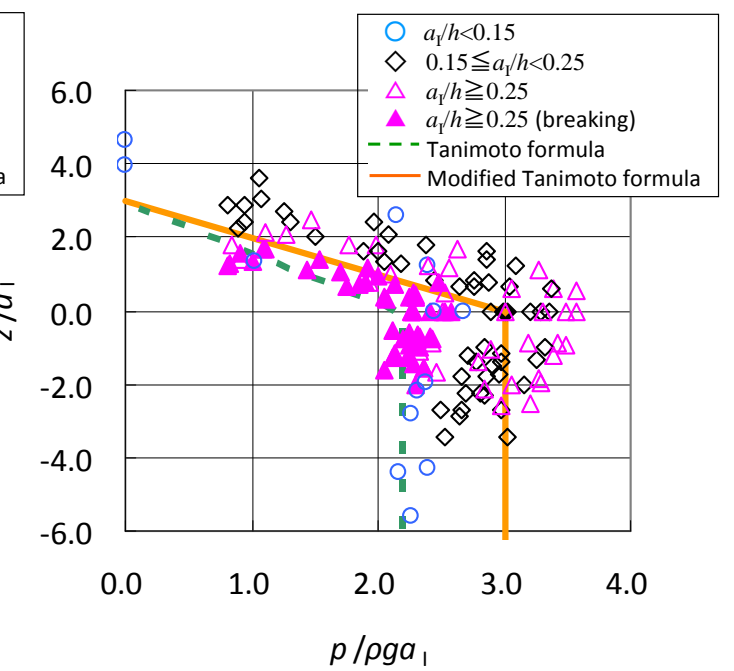

(b) High-crested caisson $\left(h_{\mathrm{C}} / H_{\mathrm{D}}=1.0\right)$

Figure 10. Non-dimensional horizontal pressure distributions.

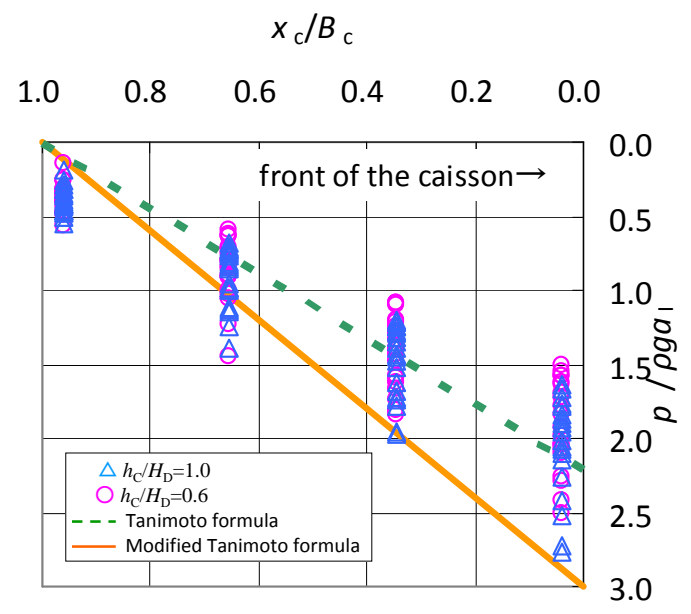

Figure 11. Non-dimensional uplift pressure distributions.

From the discussion above, it is proposed that the horizontal pressure coefficients $\alpha$ is given by the following equation and the value of $\alpha$ varies as shown in Figure 12. As for the uplift pressure, the value of $\alpha$ is given by the constant of 2.2 regardless of $a_{\mathrm{I}} / h$. 


$$
\alpha= \begin{cases}2.2 & \left(a_{I} / h<0.15\right) \\ 1.0+8.0\left(a_{I} / h\right) & \left(0.15 \leq a_{I} / h<0.25\right) \\ 3.0 & \left(a_{I} / h \geq 0.25\right)\end{cases}
$$

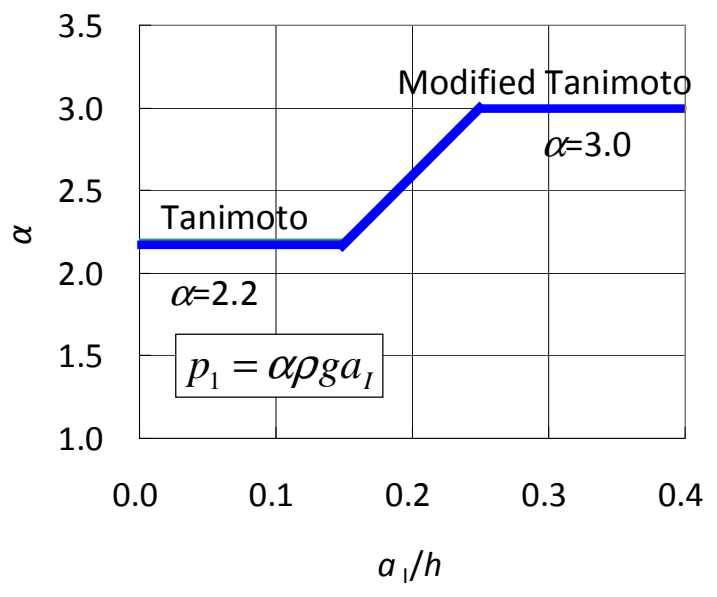

Figure 12. Proposed horizontal wave pressure coefficients $\alpha$.

\section{Proposal of Estimation Formula for The Block Armored Breakwater}

The ratio of the measured tsunami force on breakwater with WDW to the estimated one by the Tanimoto-type formula is defined as the pressure reduction factor for the breakwater with WDW. The reduction factors for the horizontal tsunami pressure and for the uplift pressure are represented by $\lambda_{\mathrm{H}}$ and $\lambda_{\mathrm{U}}$, respectively. Figure 13(a) shows the relationship between the horizontal tsunami pressure reduction factor $\lambda_{\mathrm{H}}$ and the relative tsunami height $a_{\mathrm{I}} / h$. When the relative tsunami height $a_{\mathrm{I}} / h$ is smaller than a value which depends on the crown height of WDW, the horizontal tsunami force reduction factor $\lambda_{\mathrm{H}}$ is roughly 1.0, and as the relative tsunami height increases, the reduction factor gradually decreases and become 0.5 to 0.6 with $a_{\mathrm{I}} / h=0.40$. This means that the tsunami force reduction of WDW is more effective for larger tsunami. The reduction factor for a high crown breakwater is large when it is compared with that of an ordinary crown breakwater. In this study, the solid line shown in Figure 13(a) is hereby proposed as the horizontal tsunami force reduction factor to be used in practical design of breakwaters with WDW. These values can be expressed by Equations (8) to (10). In the range where the relative tsunami height is small, the value of the proposed reduction factor is almost equal to the experimental data, and in the range where the tsunami height is large, it is almost the mean value of the experimental data. Figure 13(b) shows the relationship between the uplift reduction factor $\lambda_{\mathrm{U}}$ and the relative tsunami height $a_{\mathrm{I}} / h$. The tendency same as the horizontal force reduction factor $\lambda_{\mathrm{H}}$ is observed. The reduction factor for uplift force is identical to those for the horizontal force, as shown in Figure 13(b). Consequently, the tsunami wave reduction factor is given by the following equations:

$$
\begin{gathered}
\lambda=\lambda_{H}=\lambda_{U} \\
\lambda= \begin{cases}1.0 & \left(a_{I} / h<0.15\right) \\
1.27-1.8\left(a_{I} / h\right) & \left(0.15 \leq a_{I} / h\right)\end{cases} \\
\lambda=\left\{\begin{array}{ll}
1.0 & \left(a_{I} / h<0.20\right) \\
1.36-1.8\left(a_{I} / h\right) & \left(0.20 \leq a_{I} / h\right)
\end{array} \quad\left(h_{\mathrm{C}} / H_{\mathrm{D}}=0.6\right)\right.
\end{gathered}
$$

Based on the tsunami wave reduction factor, horizontal and uplift tsunami pressure $p_{1 \mathrm{~B}}$ and $p_{\mathrm{UB}}$ can be estimated as follows. As for the acting height $\eta_{\mathrm{B}} *$ of the wave pressure, no significant difference due to the WDW was observed. Therefore no modification was made for the wave pressure acting height. 


$$
\begin{gathered}
\eta_{B}^{*}=\eta^{*}=3.0 a_{I} \\
p_{1 B}=\alpha \lambda \rho g a_{I} \\
p_{U B}=2.2 \lambda \rho g a_{I}
\end{gathered}
$$

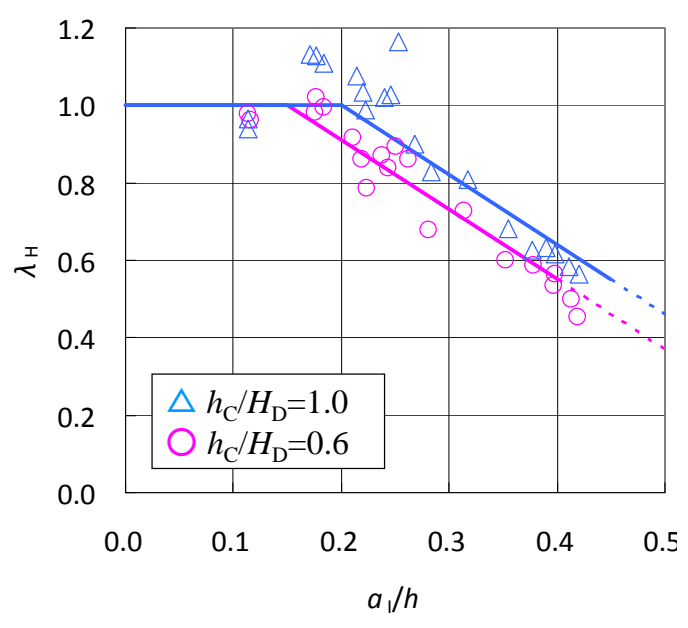

(a) Horizontal wave force

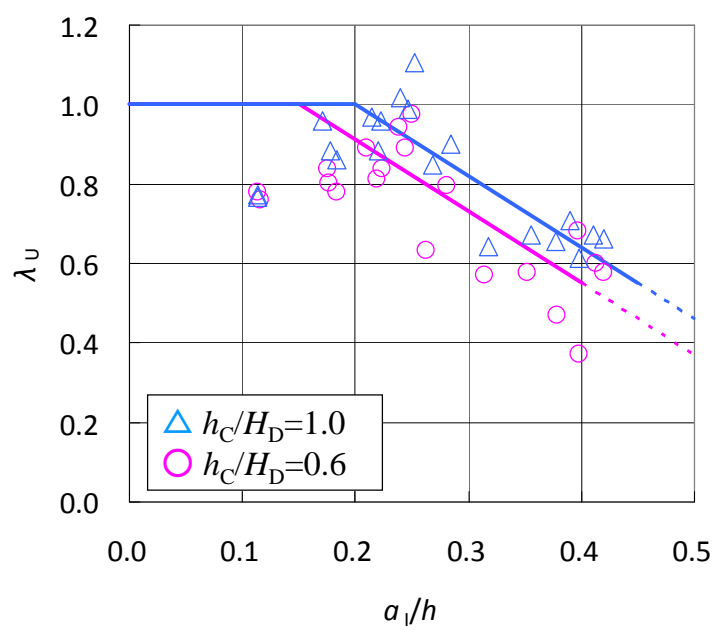

(b) Uplift force

Figure 13. Tsunami wave reduction factor.

Figures 14 (a) and (b) shows the comparison between the experimental and predicted tsunami forces for the breakwater with WDW. The high correlation between the experiments and prediction demonstrates the good applicability of the proposed formula.

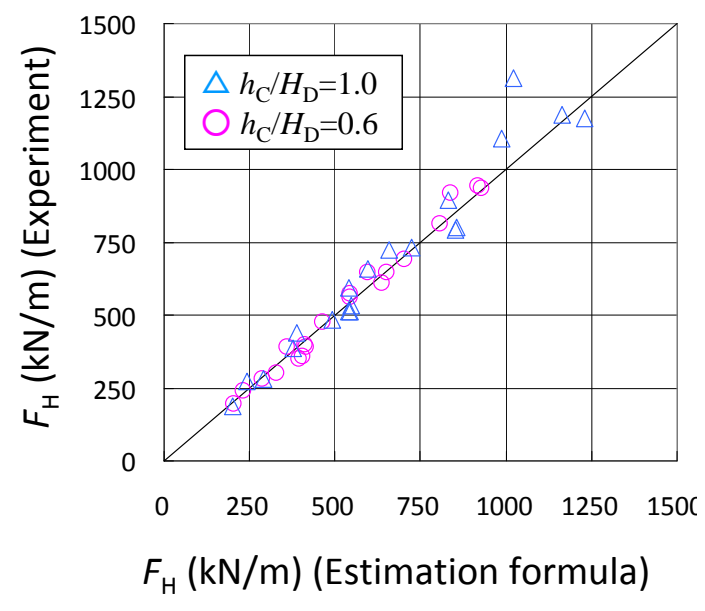

(a) Horizontal wave force

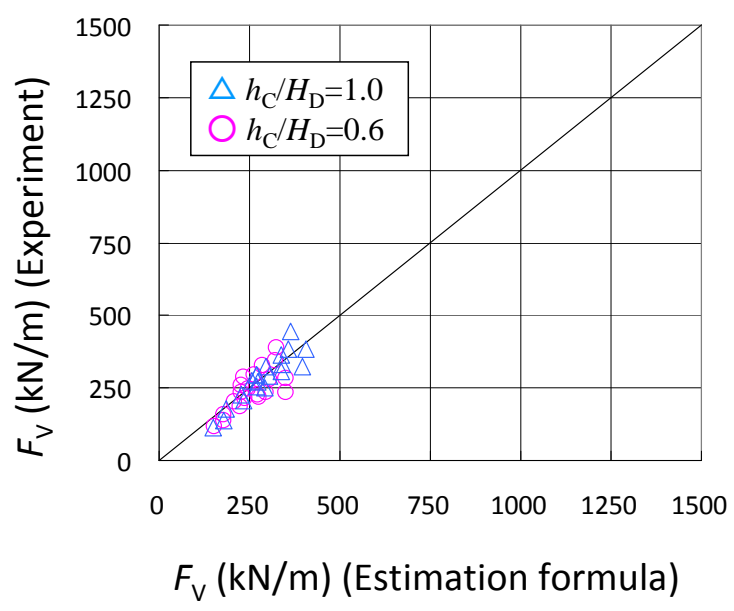

(b) Uplift force

Figure 14. Measured and predicted tsunami forces.

\section{EXPERIMENTS ON THE STABILITY OF WAVE-DISSIPATING BLOCK AGAINST TSUNAMI}

\section{Experimental Conditions}

If the WDW was unstable to the tsunami, it is said that the effectiveness of WDW against tsunami will be decreased. Therefore the stability of wave-dissipating concrete block was confirmed. Table 3 summarizes the dimensions of the breakwater. The cross section of the breakwater is the same as that in the tsunami wave force experiment shown in Figure 5. The water depth was kept constant as $12.0 \mathrm{~m}$. The test started with a small tsunami, which did not cause damage, and the tsunami height was 
gradually increased. Because the purpose of this test is to assess the stability of wave-dissipating blocks against a single tsunami, the test section was rebuilt after each tsunami attack. In this experiment, the stability of the wave-dissipating concrete blocks is checked by the damage ratio $D$ defined by:

$$
D(\%)=100 \times \frac{n}{N}
$$

where $N$ is the total number of the wave-dissipating blocks, $n$ is the number of dislocated blocks. The dislocation was defined as the movement more than its length from its initial position or the rotation more than $90^{\circ}$. The number of dislocated blocks was counted by visually observing and analyzing the photographs taken before and after the tsunami attack.

Case 1 is an experiment for blocks with the required mass estimated by the design wave height $H_{\mathrm{D}}$ corresponding to the water depth at the breakwater. The crown height of the caisson is set as $h_{\mathrm{C}}=$ $0.6 H_{\mathrm{D}}$, which is the same condition as Case 3-1 in the wave force experiment. On the other hand, in the Cases 2 and 3, assuming the breakwater is installed in the inner bay area, the design wave height $H_{\mathrm{D}}$ is relatively small. This was determined by applying the block mass and $K_{\mathrm{D}}$ value of the block 8.3 to the Hudson formula. The crown height of the caisson was determined as 0.6 times the design wave height. The experimental case covers all the areas to be considered in actual breakwater design including both a non-breaking and breaking tsunami.

\begin{tabular}{|c|c|c|c|c|c|c|c|}
\hline \multicolumn{8}{|c|}{ Table 3. Dimensions of breakwater models. } \\
\hline Case & $\begin{array}{c}\text { Water } \\
\text { depth } \\
h(\mathrm{~m})\end{array}$ & $\begin{array}{l}\text { Mound } \\
\text { depth } \\
h^{\prime}(\mathrm{m})\end{array}$ & $\begin{array}{c}\text { Design } \\
\text { wave } \\
\text { height } \\
H_{\mathrm{D}}(\mathrm{m})\end{array}$ & & $\begin{array}{l}\text { ght of } \\
\text { on }\end{array}$ & $\begin{array}{c}\text { Block } \\
\text { mass } \\
M(\mathrm{t})\end{array}$ & $\begin{array}{c}\text { Crown } \\
\text { width } \\
\text { of WDW } \\
B(\mathrm{~m})\end{array}$ \\
\hline 1 & \multirow{3}{*}{12.0} & \multirow{3}{*}{8.4} & 6.9 & 4.1 & $\left(0.6 H_{D}\right)$ & 36.8 & 5.9 \\
\hline 2 & & & 4.1 & 2.5 & $\left(0.6 H_{D}\right)$ & 7.4 & 3.4 \\
\hline 3 & & & 3.2 & 2.0 & $\left(0.6 H_{D}\right)$ & 3.7 & 2.8 \\
\hline
\end{tabular}

\section{Experimental Results}

No damage was observed in Case 1. Figure 15 shows the relationship between $a_{\mathrm{I}} / H_{\mathrm{D}}$ and the damage ratio $D(\%)$ in Case 2 and Case 3 in which damage occurred. Damage of the blocks occurred in the portion above the still water level during tsunami uprush. Blocks riding on the crown of the caisson and falling behind the caisson were observed. In the stability tests for random wind waves, the motion of blocks in the offshore direction during wave run down is frequently observed. Such behavior was not observed in the experiment for tsunami. The damage ratio was less than $1.0 \%$ for a tsunami height 1.5 times higher than the design wave height for the blocks. The maximum damage ratio in all cases was about $1.5 \%$. Therefore, it can be said that damage that would give bad affection on the tsunami wave force reduction does not occur.

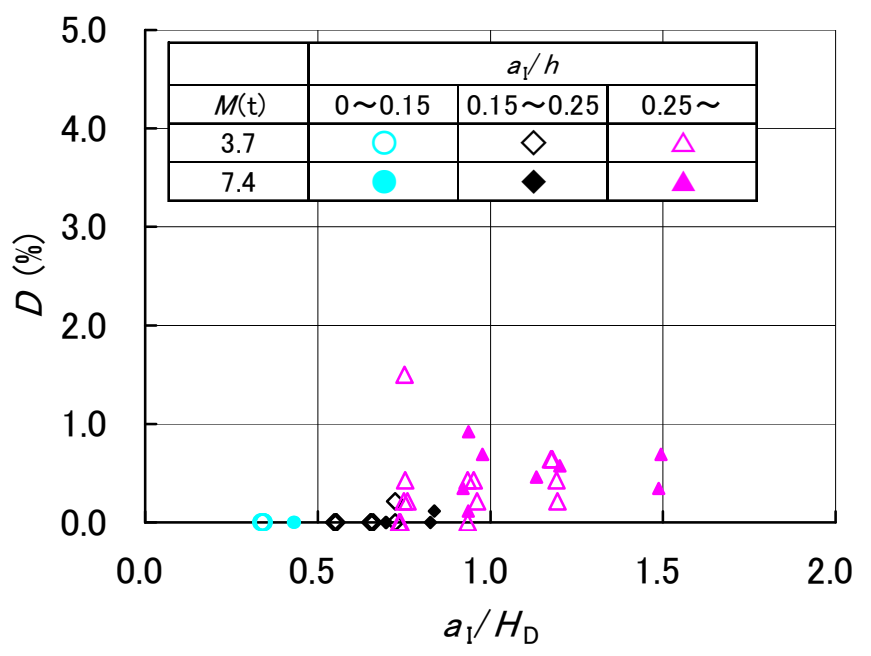

Figure 15. Stability test results. 


\section{CONCLUSIONS}

The following main conclusions can be drawn from the present study:

1. The profile of the first soliton is uniquely determined by the water depth and wave height. It can be well expressed by the solitary wave theory.

2. The applicable range and the value of the tsunami pressure coefficient for the Tanimoto and modified Tanimoto formula were clarified through the various experiments.

3. As for the uplift pressure, it was confirmed that the modified Tanimoto formula gives the overestimation. The original Tanimoto formula is more suitable for the estimation of the uplift pressure because the effect of impulsive pressure does not affect the uplift pressure.

4. The tsunami force reduction factor of WDW shows same value between the horizontal and uplift forces and differs with the crown height of WDW as shown in Equations (9) and (10).

5. Wave-dissipating concrete blocks with required mass estimated by the design wave height corresponding to the water depth were sufficiently stable even against a tsunami with soliton fission.

6. The damage ratio of the wave-dissipating concrete block was about $1.0 \%$ for a tsunami 1.5 times higher than the designed wave height. It was confirmed that the block damage that would give bad affection on tsunami force reduction did not occur.

\section{REFERENCES}

Ikeno, M, Matsuyama, M, Sakakiyama, T. and Yanagisawa, K. (2006). Effects of Soliton Fission and Wave Breaking on Tsunami Force Acting on Breakwater, Proc. 30th International Conf. Coastal Eng., ASCE, pp.5162-5174.

Iwasaki, T. and Suzuki, Y. (1977). Transformation and Breaking of Solitons Dispersed from Impulsive Bores, Proc. 24th Japanese Conf. Coastal Eng., pp.45-49. (in Japanese)

Iwasaki, T., Shuto N., Suzuki, Y. and Kurita, S. (1978). Sorting Distance of Impulsively Generated Waves, Proc. 25th Japanese Conf. Coastal Eng., pp.132-136. (in Japanese)

Kashima, H. and Hirayama, K. (2013). Model experiments and Numerical Simulations on Tsunami with Soliton fission in Kuji Harbor, Journal of JSCE, Ser. B3 (Ocean Eng.), Vol. 69, No. 2 p. I_694-I_699. (in Japanese)

Maruyama, S., Takayama, T., Shimosako, K., Yahiro, A., Suzuki, K., Aota, T., Tanaka, M., Matsumoto, A. and Hanzawa, M. (2015). Wave Force Reduction Effect of Wave-Dissipating Works Against Tsunami with Soliton Fission, Proc. Coastal Structures \& Solutions to Coastal Disasters Joint Conference 2015. (in press)

Ministry of Land, Infrastructure, Transport and Tourism of Japan (MLIT), Port and Harbor Bureau (2013) "Guidelines for Tsunami-Resistant Design of Breakwaters," Available at: http://www.mlit.go.jp/common/001012142.pdf (Accessed on: 3 February 2017) (in Japanese).

Murota, A. and Iwata, K. (1968). Transformation of surges, Journal of JSCE, Vol. 160, pp.49-58. (in Japanese)

Shuto, N. (1984). The Nihonkai Chubu Earthquake Tsunami on the Northern Coast of Akita Prefecture, Proc. 31st Japanese Conf. Coastal Eng., pp.245-251. (in Japanese)

Tanimoto, K., Tsuruya, H. and Nakano, S. (1984). Experimental Study of Tsunami Force and Investigation of the Cause of Sea Wall Damage During 1983 Nihonkai Chubu Earthquake, Proc. 31st Japanese Conf. Coastal Eng., pp.257-261. (in Japanese)

Yasuda, T., Takayama, T. and Yamamoto, H. (2006). Characteristics of Deformations and Forces on Dispersive Solitons of Tsunami, Annual Journal of Coastal Eng., JSCE, Vol.53, pp.256-260. (in Japanese) 